OPEN ACCESS

Edited by: Simona Rapposelli, University of Pisa, Italy

Reviewed by: Yoko Hirata, Gifu University, Japan Andrea Tarozzi, University of Bologna, Italy

*Correspondence: Paola Costanzo paola.costanzo@unical.it Manuela Oliverio m.oliverio@unicz.it

Specialty section: This article was submitted to Medicinal and Pharmaceutical Chemistry,

a section of the journal

Frontiers in Chemistry

Received: 14 July 2021 Accepted: 04 October 2021 Published: 19 October 2021

Citation: Costanzo P, Oliverio M, Maiuolo J, Bonacci S, De Luca G, Masullo M, Arcone R and Procopio A (2021) Novel Hydroxytyrosol-Donepezil Hybrids as Potential Antioxidant and Neuroprotective Agents.

Front. Chem. 9:741444. doi: 10.3389/fchem.2021.741444

\section{Novel Hydroxytyrosol-Donepezil Hybrids as Potential Antioxidant and Neuroprotective Agents}

\author{
Paola Costanzo ${ }^{1 *}$, Manuela Oliverio ${ }^{2 *}$, Jessica Maiuolo ${ }^{2}$, Sonia Bonacci ${ }^{2}$, \\ Giuseppina De Luca ${ }^{1}$, Mariorosario Masullo ${ }^{3,4}$, Rosaria Arcone ${ }^{3,4}$ and Antonio Procopio ${ }^{2}$ \\ ${ }^{1}$ Dipartimento di Chimica e Tecnologie Chimiche, Università della Calabria, Rende, Italy, ${ }^{2}$ Dipartimento di Scienze della Salute, \\ Università Magna Græcia di Catanzaro, Catanzaro, Italy, ${ }^{3}$ Dipartimento di Scienze Motorie e del Benessere, Università degli Studi \\ di Napoli "Parthenope", Napoli, Italy, ${ }^{4}$ CEINGE Biotecnologie Avanzate S.C.a R.L., Napoli, Italy
}

It is well-accepted that the endogenous antioxidant protection system progressively decays in elderly people, and that the oxidative stress contributes to different neurodegenerative disorders such as Alzheimer's Diseases (AD). The lower incidence of $A D$ in countries which feature the Mediterranean Diet was associated to the high consumption of extra virgin olive oil and its polyphenolic fraction, in particular hydroxytyrosol. The protective role of these bio-phenols against oxidative stress, suggested that we combine their antioxidant/free radical scavenging activity with donepezil, an active ingredient which has just been approved for the treatment of AD. Different synthetic strategies were tested to conjugate the two different synthons in good yields. Additionally, a nitro-hydroxytyrosol derivative was synthesized to extend the application to other neurodegeneration inflammatory models. Then, their bioactivity was measured in different chemical and biological tests on a human neuroblastoma cell line (SHSY-5Y). Remarkable results on cell viability and the regulation of the redox state of cells were obtained. All hybrids showed negligible cell death under $1 \mu \mathrm{M}$ and are stable and non toxic. Reactive oxygen species (ROS) measurements showed that the nitrohybrid was the more effective one at reducing the ROS amount to physiological values. Then, in light of the bio-metal hypothesis of diverse neurodegenerative disorders, we tested these new compounds on the chelation properties of redox-active metals. The nitro-hybrid was able to chelate all of the tested metal cations, suggesting that we propose it as potential lead compound for a new class of neuroprotective antioxidant agents.

Keywords: antioxidant, bio-phenols, neurodegeneration, bio-metal chelator, reactive oxygen species

\section{INTRODUCTION}

With longer life expectancies and aging thanks to the modern medical advances as well as social and environmental conditions, neurological disorders are increasing. Neurodegenerative diseases, as other age-related conditions such as diabetes, cardiovascular diseases, sarcopenia, and cancer are also associated with the so-called "oxidative stress theory of aging" (Liguori et al., 2018). In physiological conditions, the production of free radicals like the reactive oxygen species (ROS) is counterbalanced by the antioxidant systems, but in pathological conditions, or elderly peoples, the antioxidant defenses are not still to balance the ROS formation anymore. For these reasons many efforts have been made to develop new drugs with antioxidant and scavenging activities (Maiuolo et al., 2017; 
Neha et al., 2019). In particular, the excessive production of ROS contributing to oxidative stress leads to neuronal cell death and altered brain function (Singh et al., 2019). The greater sensitivity of the brain to oxidative stress could be explained by its high oxygen demand and consumption, as well as the presence of redox-active metals, such as iron and copper, which is increased in the brains of Alzheimer's disease (AD) and Parkinson's disease (PD) patients (Barnham and Bush, 2008). During the last decades many reviews and papers have demonstrated the role of oxidative stress in the pathogenesis of these neurodegenerative diseases, and the administration of both natural and synthetic antioxidant molecules was studied in diverse clinical trials (Blesa et al., 2015; Kim et al., 2015; Ganguly et al., 2021). The beneficial effects of the Mediterranean diet against age-related cognitive decline have been highlighted (Gardener and Caunca, 2018; Balakrishnan et al., 2021), and they were associated to the high consumption of olive oil (Kalatsbari, 2013). It was recently revealed that the poly(phenolic) components of extra virgin olive oil could be neuroprotective and ameliorative against these diseases, by working on several clinical biomarkers and molecular targets (Spagnuolo et al., 2016; Dinda et al., 2019). The beneficial health effects of the phenolic fraction in virgin and/or extra virgin olive oil are due to the secoiridoids oleuropein and ligstroside, together with its derivatives: aglycones (Leri et al., 2018), oleocanthal (Batarseh et al., 2018), oleacein (Cuyàs et al., 2019), tyrosol and hydroxytyrosol (St-LaurentThibault et al., 2011; Bulotta et al., 2013; Crespo et al., 2017). Different mechanisms for the neuroprotective action of these natural compounds were hypothesized. The main mechanisms studied were free radical scavenging/antioxidant actions, antiinflammatory effects, and antiapoptotic properties (Kalatsbari, 2013). Furthermore, the recent literature showed an important effect of different nitro-hydroxytyrosol derivatives on PD inflammatory models, demonstrating that the antioxidant properties of the ortho-diphenol moiety could be extended with the right modifications (Gallardo et al., 2014). And considering the multifactorial origins of these disorders, the study of nature inspired multitarget direct ligands with antioxidant and biometal chelating activity remains of interest (Costa et al., 2020; Cui et al., 2020). Donepezil, the second drug approved by the FDA for the treatment of $\mathrm{AD}$, is the most commonly used pharmacophore for the design of novel derivatives, with a potential multifunctional activity (Unzeta et al., 2016; Li et al., 2018). In the last few years, the $\mathrm{N}$-benzylpiperidine synthon was combined with natural compounds such as ferulic acid or curcumine (Xu et al., 2016; Dia et al., 2017) in order to obtain a new series of donepezil hybrids with potent cholinesterase inhibitory activities, radical scavenging activities and metal-chelating properties. Then, based on our experiences on the green manipulation of oleuropein and its derivatives (Oliverio et al., 2016; Costanzo et al., 2018; Cariati et al., 2019; Oliverio et al., 2021) and the sustainable synthesis of bioactive compounds (Costanzo et al., 2016; Caliandro et al., 2018), we decided to investigate the neuroprotective features of the olive oil polyphenols as multitarget drug candidates for the treatment of Alzheimer's disease. Herein, we reported the design, synthesis, characterization and biological tests of new donepezil hybrids with hydroxytyrosol (Figure 1). Furthermore, in order to extend the cognitive effect of these donepezil derivatives, a nitrohydroxytyrosol (NO-HT) synthon was also combined into the donepezil structure.

\section{MATERIALS AND METHODS}

\subsection{Chemistry}

\subsubsection{General Information}

All chemicals were obtained from Sigma Aldrich and Alfa Aesar, and used as received. Hydroxytyrosol was obtained as reported in literature (Gambacorta et al., 2007). MW-assisted reactions, performed in the high energy density laboratory CEM Discover Microwave were run on dynamic mode, applying a specified amount of power to reach the desired temperature and pressure, working with borosilicate glass vessels equipped with silicon cap with septum. Reactions were monitored by TLC using silica plates 60-F264 on alumina, commercially available from Merk. Liquid flash chromatography was performed on a Supelco VERSA FLASH HTFP station using silica cartridges commercially available from Supelco. ${ }^{1} \mathrm{H}-\mathrm{NMR}$ and ${ }^{13} \mathrm{C}-\mathrm{NMR}$ spectra were recorded on a Bruker WM 300 instrument on samples dissolved in $\mathrm{CDCl}_{3}$ (compounds HT1a, HT3, HT4, HT3a, HT4a) or in $\mathrm{d}_{6}$-DMSO (compounds HT1 and HT2). Chemical shifts are given in parts per million (ppm) from tetramethylsilane as the internal standard (0.0 ppm). HRMS measurements were realized on a Thermo Scientific QExactive (Thermo Fisher, Milan, Italy) mass spectrometer working in positive mode at 35,000 resolving power, operating in SIM mode by flow injection (flow rate $15 \mu \mathrm{l} / \mathrm{min}$ for each stock solution). Stock solutions at a concentration of $1 \mathrm{mg} / \mathrm{ml}$ were prepared in UHPLC-MS grade $\mathrm{MeOH}$ for each analyte separately. Prior to analysis, each solution was diluted 1:1,000 (v/v) in a vial to obtain a concentration of $1 \mathrm{mg} / \mathrm{L}$. Detection of the targeted compounds was based on theoretical exact mass. Data were evaluated by Xcalibur 2.2.SP1 (Thermo Fisher Scientific, Bremen, Germany). The mass accuracy, directly calculated from Xcalibur, is defined by the formula $\Delta(\mathrm{ppm})=$ [(theoretical mass - measured mass)/theoretical mass] $\times$ 1.000.000. The ORAC assay employed a microplate fluorimeter (Victor 2 multilabel counter, PerkinElmer Life Sciences, Waltham, MA, United States; excitation at $495 \mathrm{~nm}$; emission at $535 \mathrm{~nm}$; $0.5 \mathrm{~s}$ per reading from the bottom of the plate; 1 reading per min) and 24-well plates. Absorption measurements for the CUPRAC assay and the metal-chelating properties characterization were performed on a Perkin-Elmer Lambda 35 spectrophotometer.

\subsubsection{General Protocol for the Synthesis of $\mathrm{N}$-Benzylpiperidine-4-Carboxylic Acid}

The method for the ester hydrolysis was adapted from the procedure developed by Theodorou et al. (2007). Ethyl $N$-benzylpiperidine-4-carboxylate $(1.08 \mathrm{~g}, 4.37 \mathrm{mmol})$ was dissolved in $20 \mathrm{ml}$ of dichloromethane:methanol (9:1). Then, $3.0 \mathrm{ml}$ of $\mathrm{NaOH}$ in methanol $(2 \mathrm{~N})$ were added, and the mixture is reacted for $24 \mathrm{~h}$ at room temperature and 


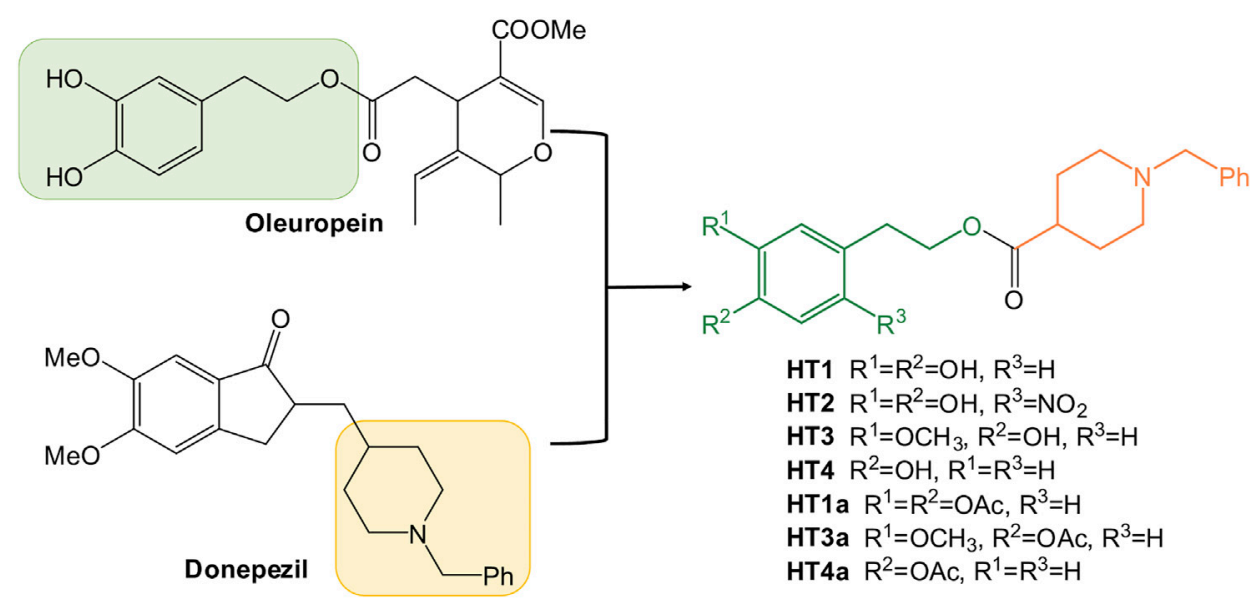

FIGURE 1 | Development of new hydroxytyrosol-donepezil hybrids.

monitored by TLC. After $24 \mathrm{~h}, 1.0 \mathrm{ml}$ of the basic solution was added, and the mixture was stirred for another $24 \mathrm{~h}$. At the end of the reaction, the solvent was removed under reduced pressure, the residue was diluted with water and extracted three times with diethyl ether. The water phases were collected, cooled at $0^{\circ} \mathrm{C}$, and acidified with $\mathrm{HCl}(6 \mathrm{~N})$ till $\mathrm{pH}=2 \div 3$. Finally, the water phase was extracted three times with ethyl acetate. The organic phases were collected, dried with $\mathrm{Na}_{2} \mathrm{SO}_{4}$, filtered, and evaporated under reduced pressure. The product was used without further purification procedures.

\subsubsection{General Protocol for the Synthesis of the Donepezil Hybrids}

The best reaction conditions developed for the synthesis of donepezil hybrids are described below. To a solution of $\mathrm{N}$-benzylpiperidine-4-carboxylic acid (50 mg, $0.23 \mathrm{mmol}$ ) THF $(5 \mathrm{ml})$, the desired polyphenolic alcohol (10 equivalents) and trimethylsilyl chloride (CTMS, 2.5 equivalents) were added in a 2necked round bottom flask equipped with a magnetic stirrer and a condenser. The mixture was heated at $40^{\circ} \mathrm{C}$ for 6 days. Subsequently, the solvent was removed under reduced pressure, the crude was diluted in dichloromethane and was extracted three times with $\mathrm{NaHCO}_{3}$ (saturated solution). The organic phases were collected and dried with $\mathrm{Na}_{2} \mathrm{SO}_{4}$, filtered, and evaporated under reduced pressure. The product is separated from the crude by flash chromatography $\left(\mathrm{CH}_{2} \mathrm{Cl}_{2} / \mathrm{MeOH} 9.5\right.$ : $0.5 \mathrm{v} / \mathrm{v}$ ). All compounds (HT1, HT3, and HT4) were identified by HRMS and characterized by ${ }^{1} \mathrm{H}-\mathrm{NMR}$ and ${ }^{13} \mathrm{C}-\mathrm{NMR}$ (See Supplementary Material).

The microwave-assisted synthesis of the acetylated compounds (HT1a, HT3a, and HT4a) were done as reported in literature (Oliverio et al., 2016). All compounds were identified by HRMS and characterized by ${ }^{1} \mathrm{H}-\mathrm{NMR}$ and ${ }^{13} \mathrm{C}-\mathrm{NMR}$ (See Supplementary Material).

The synthesis of the nitro-derivative was obtained with the procedure reported in literature (Trujillo et al., 2014). Briefly, HT1 (55 mg, $0.155 \mathrm{mmol}$ ) was dissolved in AcOH/AcONa buffer
$(\mathrm{pH}=3.75,31 \mathrm{ml}) . \mathrm{NaNO}_{2}(21.4 \mathrm{mg}, 0.31 \mathrm{mmol})$ was added, and the mixture was stirred at room temperature in the dark for $30 \mathrm{~min}$. Then, the aqueous solution was extracted three times with ethyl acetate. The organic phases were collected and dried with $\mathrm{Na}_{2} \mathrm{SO}_{4}$, filtered, and evaporated under reduced pressure. The product is separated from the crude by flash chromatography $\left(\mathrm{CH}_{2} \mathrm{Cl}_{2} / \mathrm{MeOH} / \mathrm{TEA}\right.$ 9.5:0.4:0.1 v/v).

\subsection{In Vitro Antioxidant Activities 2.2.1 Measurement of Oxygen Radical Absorbance Capacity}

The Orac assay was performed as reported in literature (Nardi et al., 2017) with slight modifications on the solvent solution. Briefly, $7 \%$ randomly methylated $\beta$-cyclodextrin (RMCD) solution (acetone/water/DMSO, 49.5:49.5:1 v/v) was used as the solvent for the Trolox standards and as a blank. The unprotected donepezil hybrids $(10 \mu \mathrm{M})$ in this $7 \%$ RMCD solution were used as samples. To each well, $80 \mu \mathrm{l}$ of sample, blank or Trolox (1.25, $6.25,12.5,25,50$ and $100 \mu \mathrm{M}$ in $7 \%$ RMCD solution) were added to $800 \mu \mathrm{l}$ of disodium fluorescein solution (FL, $14 \mu \mathrm{M}$ in PBS, pre-incubated at $37^{\circ} \mathrm{C}$ for $15 \mathrm{~min}$ ). Each solution was analysed in duplicate in a "forward-then-reverse" order as described in the literature (Ou et al., 2001). Reactions were initiated by the addition of $300 \mu \mathrm{l}$ of AAPH $(31.7 \mathrm{mM}$ in PBS). The measurement temperature was set at $37^{\circ} \mathrm{C}$. A regression equation was built by comparing the net area under the FL decay curve and the Trolox concentration according to the following equation:

$$
Y(\mu \mathrm{M} \text { Trolox })=a+b X(\mathrm{AUC}-n)
$$

and the final $\mathrm{ORAC}_{\mathrm{FL}}$ values were expressed as Trolox equivalents $\left(\mu \mathrm{mol} \mathrm{g}^{-1}\right)$. The area under the curve was calculated with the following equation:

$$
\mathrm{AUC}=1+\sum_{i=1}^{i=45} f_{1} / f_{0}
$$




\subsubsection{Cupric Ion Reducing Antioxidant Capacity Method}

The CUPRAC test was performed as reported by Ozyürek et al. (2008) on the new compounds in the unacetylated form.

\section{Preparation of Solutions}

$\mathrm{CuCl}_{2}$ solution $10 \mathrm{mM}$, was prepared by dissolving $0.336 .1 \mathrm{~g}$ $\mathrm{CuCl}_{2}$ in water, and diluting to $250 \mathrm{ml}$. Neocuproine (Nc) solution $7.5 \mathrm{mM}$, was prepared by dissolving $15 \mathrm{mg}$ of neocuproine in $10 \mathrm{ml}$ of absolute $\mathrm{EtOH}$. Ammonium acetate $1.0 \mathrm{M}$ was prepared by dissolving $19.27 \mathrm{~g}$ of $\mathrm{NH}_{4} \mathrm{Ac}$ in $250 \mathrm{ml}$ of water. The cyclodextrin $(2 \% \mathrm{M}-\beta-\mathrm{CD})$ stock solution was prepared in water-acetone $(9: 1 \mathrm{v} / \mathrm{v})$. The standard solution of Trolox $1 \mathrm{mM}$ was prepared in $2 \% \mathrm{M}-\beta-\mathrm{CD}$. All working solutions of antioxidant $1 \mathrm{mM}$ were freshly prepared in $2 \% \mathrm{M}-\beta-\mathrm{CD}$.

$1 \mathrm{ml}$ of $\mathrm{Cu}(\mathrm{II})+1 \mathrm{ml}$ of $\mathrm{Nc}+1 \mathrm{ml}$ of $\mathrm{NH}_{4} \mathrm{Ac}$ buffer $+x \mathrm{~mL}$ of antioxidant solution $+(1.1-x) 2 \% \mathrm{M}-\beta-\mathrm{CD}$ in 1:9 water-acetone mixture $(\mathrm{v} / \mathrm{v})$; total volume $=4.1 \mathrm{ml}$, measure $A_{450}$ against a reagent blank after $40 \mathrm{~min}$ of reagent addition at room temperature.

The Trolox equivalent antioxidant capacity (TEAC) is defined as the millimolar concentration of a Trolox solution having the antioxidant capacity equivalent to a $1.0 \mathrm{mM}$ solution of the substance under investigation. The $\mathrm{TEAC}_{\mathrm{CUPRAC}}$ values were simply calculated by dividing the molar absorptivity $\varepsilon$ of the species under investigation by that of Trolox under corresponding conditions. The concentration linearity ranges for all the antioxidants tested are reported in the Supplementary Material (See Supplementary Table S1).

\subsection{Metal-Chelating Properties}

The complexing studies for all the unprotected hybrids were carried out through a UV-vis spectroscopy assay with the wavelength ranging from 200 to $400 \mathrm{~nm}$. The unprotected hybrids were dissolved in a 5\% DMSO methanolic solution $(3 \mathrm{mM})$. This solution was diluted with methanol to $150 \mu \mathrm{M}$. $2 \mathrm{ml}$ of the $150 \mu \mathrm{M}$ solution were mixed with $2 \mathrm{ml}$ of methanol to record the spectra of the hybrids alone, or with $2 \mathrm{ml}$ of the salts solution $(300 \mu \mathrm{M})$. Then, the absorption spectra of the antioxidants $(75 \mu \mathrm{M})$ alone or in the presence of $\mathrm{CuSO}_{4}$, $\mathrm{FeSO}_{4}, \mathrm{FeCl}_{3}$ or $\mathrm{ZnCl}_{2}(150 \mu \mathrm{M})$ mixed for $30 \mathrm{~min}$ in methanol at room temperature were recorded in a $1 \mathrm{~cm}$ quartz cell.

\subsection{In Vitro Assays}

The human SH-SY5Y neuroblastoma cell line was purchased with eight passage numbers from the American Type Culture Collection (20099 Sesto San Giovanni, Milan, Italy), and maintained in Dulbecco's modified Eagle's medium (DMEM) (Sigma-Aldrich Ltd.) supplemented with 10\% fetal bovine serum (FBS), $100 \mathrm{U} / \mathrm{ml}$ penicillin, $100 \mu \mathrm{g} / \mathrm{ml}$ streptomycin, into a humidified $5 \% \mathrm{CO}_{2}$ atmosphere at $37{ }^{\circ} \mathrm{C}$ ). Before carrying out the treatments, the neurons were differentiated using $10 \mu \mathrm{M}$ of all-trans retinoid acid (Sigma Aldrich, 20151 Milan, Italy) for 5 days and maintaining a concentration of FBS at $1 \%$. Following differentiation, when the cell lines reached a $70 \%$ confluence they have been suitably plated to carry out biologic tests.

\subsubsection{MTT Assay}

The MTT test is based on the observation that live cells can reduce the water-soluble yellow tetrazolium salt [3-(4,5dimethylthiazol-2-yl)-2,5-diphenyltetrazolium bromide] into water-insoluble blue/magenta formazan crystals, by dehydrogenase of the active mitochondria. Dissolved formazan crystals can be quantified using a spectrophotometer and the values obtained are in direct correlation to the number of metabolically active cells. For this reason, this colorimetric assay is used to evaluate cell viability.

The MTT assay was performed as reported in literature (Corasaniti et al., 2007). SH-SY5Y were placed in 96-well microplates at a density of $6 \times 10^{3}$ and, the next day, were treated with the donepezil hybrids for $24 \mathrm{~h}$. Subsequently, the medium was replaced with a phenol red-free medium containing MTT solution $(0.5 \mathrm{mg} / \mathrm{ml})$ and, after $4 \mathrm{~h}$ incubation, $100 \mu \mathrm{l}$ of $10 \%$ SDS was added to each well to solubilize the formazan crystals.

The optical density was measured at wavelengths of 540 and $690 \mathrm{~nm}$ using a spectrophotometer (X MARK Spectrophotometer Microplate Bio-Rad).

In the last experiment, SH-SY5Y cells were treated with donepezil hybrids for $21 \mathrm{~h}$ at the concentrations shown in the Figure 5C. After that, the cells were exposed to $\mathrm{H}_{2} \mathrm{O}_{2}(100 \mu \mathrm{M}$, $3 \mathrm{~h}$ ), and cell viability was measured through the MTT assay as mentioned above.

\subsubsection{Measurement of Reactive Oxygen Species}

H2DCF-DA is a molecule that easily diffuses into cells and, through intracellular esterases, is split into H2DCF following the loss of the acetate group. H2DCF remains trapped within cells and is oxidized by intracellular ROS to form the highly fluorescent DCF compound. Spectrofluorimetric quantification of the DCF probe, provides the content of the ROS in the cell.

SH-SY5Y cells were plated in 96-well microplates at a density of $6 \times 10^{4}$ and, the following day, were treated with donepezil hybrids for $24 \mathrm{~h}$. At the end of the treatment period, to ensure that the compounds used were not degraded, cells were exposed to fresh donepezil hybrids for an additional 3 hours. Subsequently, the growth medium was replaced with a fresh phenol red-free medium containing H2DCF-DA $(25 \mu \mathrm{M})$. After $30 \mathrm{~min}$ at $37^{\circ} \mathrm{C}$, the cells were washed twice to remove the extracellular H2DCFDA, centrifuged, re-suspended in PBS, exposed to $\mathrm{H}_{2} \mathrm{O}_{2}(100 \mu \mathrm{M}$, $30 \mathrm{~min}$ ) and the fluorescence was evaluated by flow cytometric analysis using a FACS Accury laser flow cytometer (Becton Dickinson). The results were expressed by setting the control equal to 1 and reporting all other values. $\mathrm{H}_{2} \mathrm{O}_{2}$ alone was used as a positive control.

\subsection{Prediction of Pharmacokinetic Properties}

To analyze the drug like properties of the new hybrids, the prediction of the main pharmacokinetic properties was performed in silico. A comparison with hydroxytyrosol and donepezil was performed, too. Two free softwares "ADMETlab 
2.0" supported by Xiangya School of Pharmaceutical Sciences, Central South University ADMETlab 2.0 (2021) https:// admetmesh.scbdd.com, and "admetSAR 2.0" supported by the School of Pharmacy, East China University of Science and Technology admetSAR 2.0 (019) http://lmmd.ecust.edu.cn/ admetsar2/ were used. The main properties considered were the lipo-hydrophilic character $(\log P)$, the permeability after oral administration (Caco-2 cell permeability), and bloodbrain barrier (BBB) penetration. Finally, the agreement with Lipinski's rules was evaluated for all compounds.

\section{RESULTS}

\subsection{Chemistry}

It is thought to combine the hydroxytyrosol in the donepezil structure, in place of the indanone moiety, to obtain new hybrids with potential antioxidant and metal-chelating activity. First, considering the reactivity and sensitivity of the catechol moiety of the hydroxytyrosol (HT), we worked with the acetonide precursor (Supplementary Figure S1) of the HT in a direct oxidative condensation (Mori and Togo, 2005) and in different eco-friendly transesterification reactions (Remme et al., 2007; Climent at al., 2010), but only the Steglich esterification method has given us the hybrid in good yields (English and Williams, 2009). Unfortunately, the product was disrupted during the subsequent deprotection step. Then, we tried to use the HT directly in an old esterification reaction (Brook and Chan, 1983), as reported in Figure 2A. The HT was esterified with the $N$-benzylpiperidine-4-carboxylic acid using trimethylsilyl chloride as a reagent. This allows us to esterify the HT only on the primary alcohol and not on the phenolic -OH. This method was more advantageous due to an easy operation, mild reaction conditions, simple workup and good yields. The procedure was developed considering the chemical-physical characteristics of the selected alcohols and optimized by taking the use of non-toxic solvents into account, as possible (See Table 1). The best reaction conditions were founded working at $40^{\circ} \mathrm{C}$ in THF for 6 days (entry 3, Table 1). This protocol was applied to the other selected polyphenolic alcohols: nitro-HT (2), homovanillyl alcohol (3), and tyrosol (4). Only for the 2-nitro-HT (2) the reaction yield was low. For this reason, we decided to perform nitration reaction (Trujillo et al., 2014) directly on the hybrid HT1, with a yield of 55\% (Figure 2B). After that, in order to enhance the brain barrier permeation and the bioavailability, we carried out the acetylation of the phenolic groups using a green $\mathrm{MW}$-assisted methodology, previously developed in our laboratory (Figure 2C) (Oliverio et al., 2016). The yields for this reaction were excellent, except for the nitro-compound. In fact, the acetylated nitro hybrid, rapidly hydrolyzed the protecting group to obtain the starting unprotected analogue. Although the compound was detected by high-resolution mass spectrometry (HRMS) in the reaction crude (Supplementary Figure S2), it was not isolated in a pure form. All compounds were purified by column chromatography. The structures were verified by ${ }^{1} \mathrm{H}-\mathrm{NMR},{ }^{13} \mathrm{C}-\mathrm{NMR}$ and HRMS. The spectra and the chemical characterization can be found in the Supplementary Material.

\subsection{Metal-Chelating Properties}

In the last decades, bio-metal dyshomeostasis in the brain was associated with both AD and PD (Morris and Levenson, 2017; Squitti et al., 2017; Ashraf et al., 2018). In particular, dysregulation of $\mathrm{Cu}^{2+}, \mathrm{Zn}^{2+}, \mathrm{Fe}^{2+}$ and $\mathrm{Fe}^{3+}$ can contribute to the ROS generation via the Fenton and Habere Weiss reaction. Then, in light of the bio-metal hypothesis of the $\mathrm{AD}$ pathogenesis, we tested the unprotected phenolic hybrids on the chelation properties of these redox-active metals. Since acetylation masks the key reactive portion of the phenols structure, and considering the transient nature of the acetylation as chemical modification enhancing the cellular intake, we decided to perform the in vitro chemical test on the unprotected derivatives. As shown in Figure 3A, the compound HT1, derived from HT was able to chelate only Copper (II) efficiently. Instead, the compound HT2, i.e., the nitro-HT hybrid, chelates all the metal cations (Figure 3B).

\subsection{In Vitro Antioxidant Activities 3.3.1 Oxygen Radical Absorbance Capacity by Fluorescence}

The ORAC test for the unprotected hybrids was performed to evaluate the scavenging activity of samples against radical species. HT alone was also analyzed for comparison. The oxygen-radical absorbance capacity measured by fluorescence is a method that evaluates the antioxidant activity through a hydrogen atom transfer (HAT) mechanism. The results reported in Table 2 demonstrate that all compounds are more active than Trolox, a synthetic hydrophilic vitamin $\mathrm{E}$ analogue used as the reference compound. In particular, compound HT1 (entry 1, Table 2) is less active than HT (entry 8, Table 2), the derived alcohol, while the presence of a nitro group in HT2 reduced the antioxidant capacity by almost 3 times (entry 3 , Table 2) compared to HT1. It is worth noting that the higher value of the Trolox equivalent was founded for the compound HT3, with the homovanillyl synthon in the structure (entry 4, Table 2).

\subsubsection{Cupric Reducing Antioxidant Capacity Assay}

An evaluation of the reducing activity for the unprotected compounds was also performed. The cupric reducing antioxidant capacity test is defined as an electron transfer (ET)-based assay for the evaluation of antioxidant action. As for the ORAC test, the antioxidant capacity of the tested hybrids was experimentally measured as Trolox equivalents, and HT was also analysed for comparison. As shown in Table 2, all hybrids demonstrated antioxidant activities comparable or higher than Trolox. HT1 was the more active compound (entry 1, Table 2), showing an antioxidant capacity higher than HT on its own (entry 8 , Table 2). Otherwise, as shown in the ORAC test, the reduction in the antioxidant capacity for the nitro hybrid HT2 (entry 3, Table 2) is less pronounced, and its activity is almost high. Among the hybrids, the derivative HT4 possesses the lower antioxidant activity (entry 6, Table 2), although it is comparable with Trolox. 


\section{A}

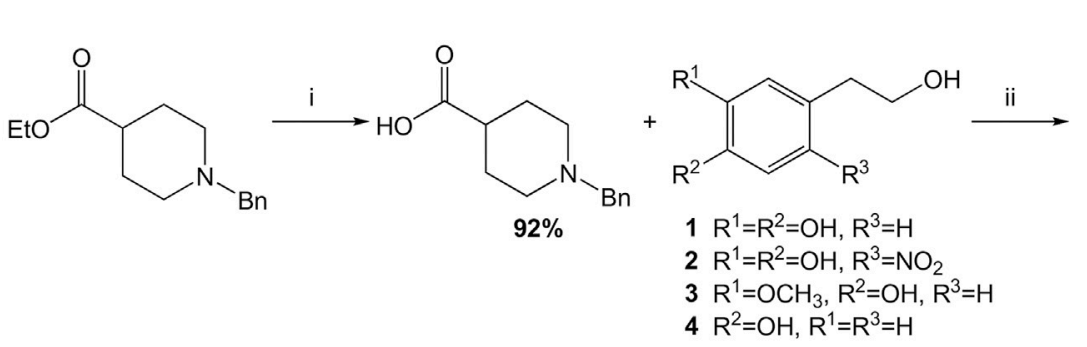<smiles>[R]c1cc([R])c(CCOC(=O)C2CCN(Cc3ccccc3)CC2)cc1[R]</smiles>

HT1 $R^{1}=R^{2}=\mathrm{OH}, \mathrm{R}^{3}=\mathrm{H} \quad(65 \%)$

$H T 2 R^{1}=R^{2}=\mathrm{OH}, \mathrm{R}^{3}=\mathrm{NO}_{2} \quad(15 \%)$

HT3 $\mathrm{R}^{1}=\mathrm{OCH}_{3}, \mathrm{R}^{2}=\mathrm{OH}, \mathrm{R}^{3}=\mathrm{H} \quad(\mathbf{5 0} \%)$

$4 \mathrm{R}^{2}=\mathrm{OH}, \mathrm{R}^{1}=\mathrm{R}^{3}=\mathrm{H}$

HT4 $\mathrm{R}^{2}=\mathrm{OH}, \mathrm{R}^{1}=\mathrm{R}^{3}=\mathrm{H} \quad(55 \%)$

B<smiles>[H][R]([H])=[R]O</smiles><smiles>[H][R16](=O)ON=C(O)[R10](=O)Nc1cc(O)c(O)cc1CCOC(=O)C1CCN(Cc2ccccc2)CC1</smiles>

C

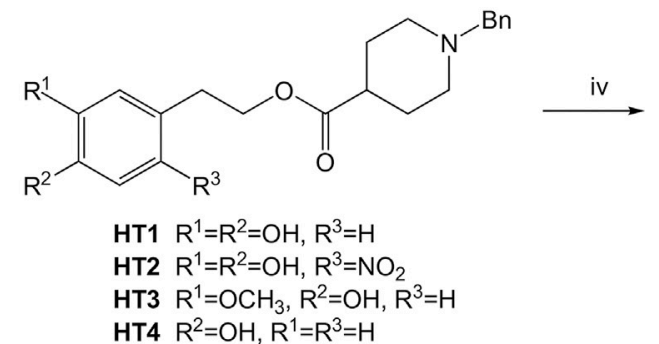

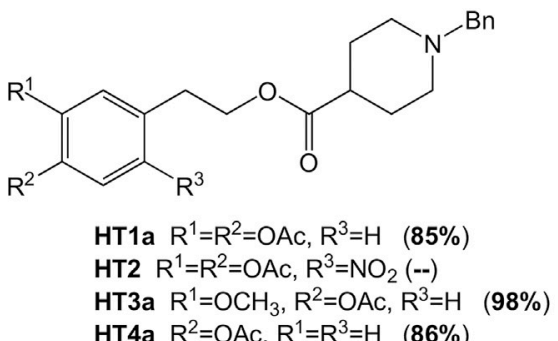

FIGURE 2 | Schematic synthesis of the donepezil hybrids. (A) Reagents and conditions: i) 1) $\mathrm{NaOH}(0.2 \mathrm{~N}), \mathrm{CH}_{2} \mathrm{Cl}_{2}-\mathrm{MeOH}$ (9:1), $48 \mathrm{~h}$; 2) $\mathrm{HCl}$ (pH = 2-3); ii) $\mathrm{CTMS}$, $\mathrm{THF}, 40^{\circ} \mathrm{C}, 6$ days. (B) Reagents and conditions: iii) $\mathrm{NaNO}_{2}, \mathrm{AcOH} / \mathrm{AcONa}$ buffer ( $\mathrm{pH}=3.75$ ), rt, dark, 30 min (C) Reagents and conditions: iv) $\mathrm{Ac}{ }_{2} \mathrm{O}$ dry, $4 \AA \mathrm{MS}, \mathrm{MW}$, $100^{\circ} \mathrm{C}, 25 \mathrm{~min}$.

TABLE 1 | Optimization of the reaction condition and synthesis of donepezil hybrids using chlorotrimethylsilane as reagent.

\begin{tabular}{|c|c|c|c|c|c|c|c|}
\hline Entry & Alcohol & Solvent & Temp. $\left({ }^{\circ} \mathrm{C}\right)$ & Time (days) & Alcohol (eq.) & CTMS (eq.) & Yield (\%) ${ }^{a}$ \\
\hline 2 & 1 & THF & r.t. & 6 & 10 & 2.5 & 42 \\
\hline 3 & 1 & THF & $40^{\circ} \mathrm{C}$ & 6 & 10 & 2.5 & 65 \\
\hline 5 & 1 & THF & Reflux & 2 & 3.4 & 7.8 & 27 \\
\hline 6 & 1 & THF & Reflux & 3 & 3.4 & 7.8 & 36 \\
\hline 7 & 2 & THF & $40^{\circ} \mathrm{C}$ & 6 & 10 & 2.5 & 15 \\
\hline
\end{tabular}

a/solated yields.

\subsection{Biological Tests}

In order to evaluate the activity of donepezil hybrids on a biological level, we tested their role on human neurons $\mathrm{SH}$ SY5Y, a neuroblastoma cell line widely used to study the neurotoxicity in vitro. First, we have assessed the impact of these compounds on cell viability in order to know their potential toxicity. Subsequently, since most neurodegenerative diseases have oxidative damage as common denominator, we wanted to study if donepezil hybrids had an antioxidant effect.

\subsubsection{Assessment of Cell Viability}

The human neuroblastoma cell line SH-SY5Y was exposed to increasing concentrations of these compounds $(0.25-100 \mu \mathrm{M})$ for $24 \mathrm{~h}$ and, under these experimental conditions, all hybrids showed negligible cell death under $1 \mu \mathrm{M}$ (Figure 4). Furthermore, data showed that all compounds are not toxic in the $1-10 \mu \mathrm{M}$ range, and are stable in these experimental conditions. In particular, a reduction in cell viability was found for compounds HT3a and HT4a at concentrations 


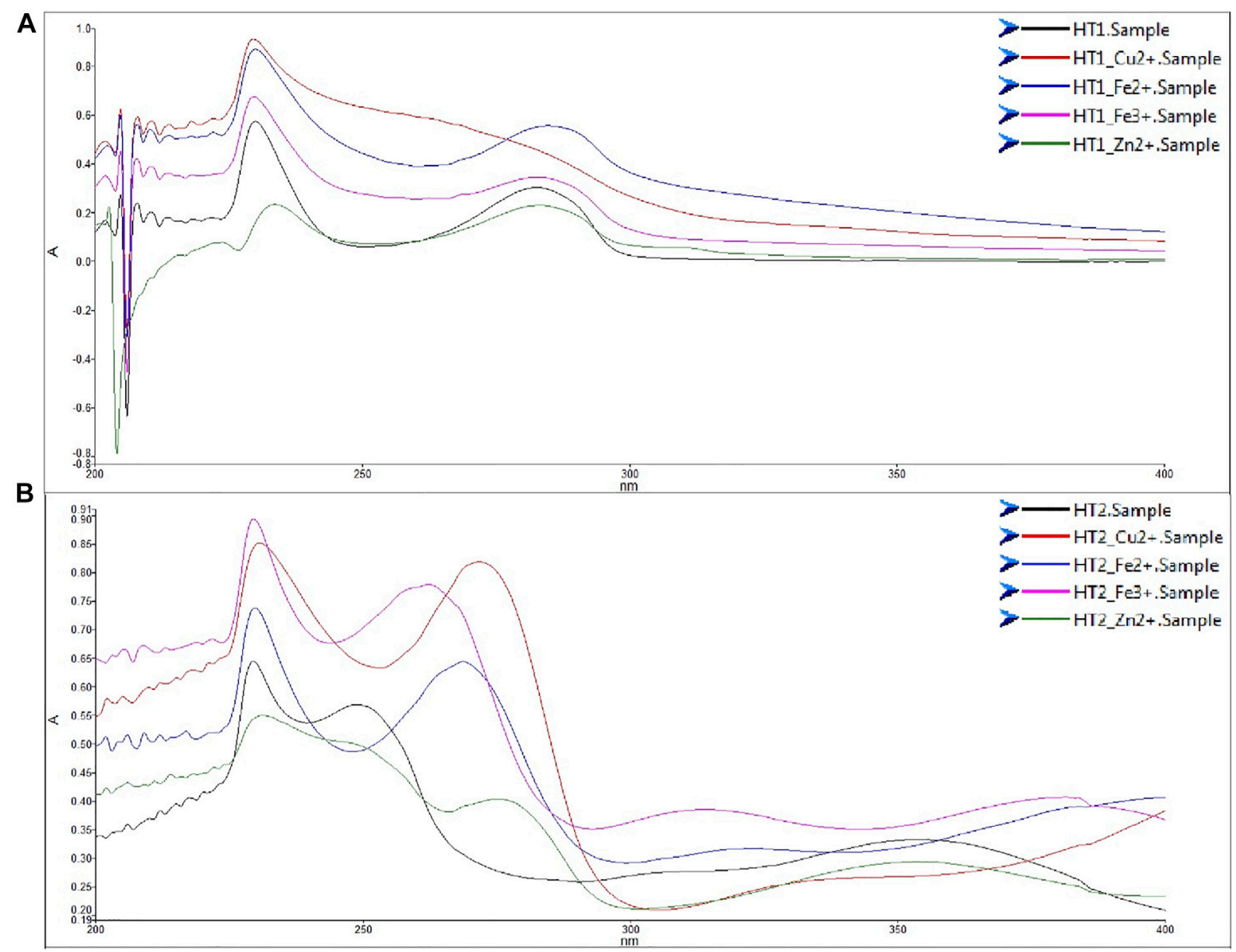

FIGURE 3 | Metal chelating activity of compounds HT1 (A) and HT2 (B). UV spectra of compounds HT1 and HT2 UV-vis (200-400 nm) absorption spectra of HT1 and $\mathrm{HT} 2(75 \mu \mathrm{M})$ alone or with $\mathrm{CuSO}_{4}(150 \mu \mathrm{M}), \mathrm{FeSO}_{4}(150 \mu \mathrm{M}), \mathrm{FeCl}_{3}(150 \mu \mathrm{M})$, or $\mathrm{ZnCl}_{2}(150 \mu \mathrm{M})$, in $\mathrm{MeOH}$.

TABLE 2 | Antioxidant activity of donepezil hybrids: effects of donepezil hybrids against ROS production induced by $\mathrm{H}_{2} \mathrm{O}_{2}$ in $\mathrm{SH}-\mathrm{SY} 5 \mathrm{Y}$ cell cultures; ORAC and CUPRAC assay.

\begin{tabular}{|c|c|c|c|c|c|c|c|c|c|}
\hline \multirow[t]{2}{*}{ Entry } & \multirow[t]{2}{*}{ Compound } & \multicolumn{6}{|c|}{ ROS measurement ${ }^{a}$} & \multirow[t]{2}{*}{ ORAC $^{b}$} & \multirow[t]{2}{*}{ CUPRAC $^{c}$} \\
\hline & & CTRL & $\mathrm{H}_{2} \mathrm{O}_{2}(100 \mu \mathrm{M})$ & $250 \mathrm{nM}$ & $500 \mathrm{nM}$ & $1 \mu \mathrm{M}$ & $10 \mu \mathrm{M}$ & & \\
\hline 1 & $\mathrm{HT} 1$ & 1 & 6.31 & 6.18 & 5.25 & 5.47 & 5.49 & $21.2 \pm 1.6$ & 3.36 \\
\hline 3 & HT2 & 1 & 6.31 & 2.21 & 1.97 & 1.12 & 1.38 & $7.6 \pm 0.2$ & 2.77 \\
\hline 4 & HT3 & 1 & 6.31 & 3.68 & 2.91 & 2.18 & 2.76 & $45.2 \pm 3.6$ & 1.80 \\
\hline 5 & НT3а & 1 & 6.31 & 2.27 & 1.94 & 1.58 & 2.13 & n.t. ${ }^{d}$ & n.t. $^{d}$ \\
\hline 9 & Trolox & n.t & n.t. & n.t. & n.t. & n.t. & n.t. & - & 1 \\
\hline
\end{tabular}

${ }^{a}$ The fluorescence values (Fitch) obtained from cytometric analysis were processed and the related quantification was conducted by setting the value of the control to 1 and comparing all other values.

${ }^{b}$ Data expressed as means \pm SEM of three independent observations $\left(\mu \mathrm{mol}\right.$ trolox $\left.\mathrm{I}^{-1}\right)$.

${ }^{c}$ Data are expressed as ( $\mathrm{mmol}$ of trolox)/(mmol of tested compound).

${ }^{\text {n.t. }}=$ not tested. 

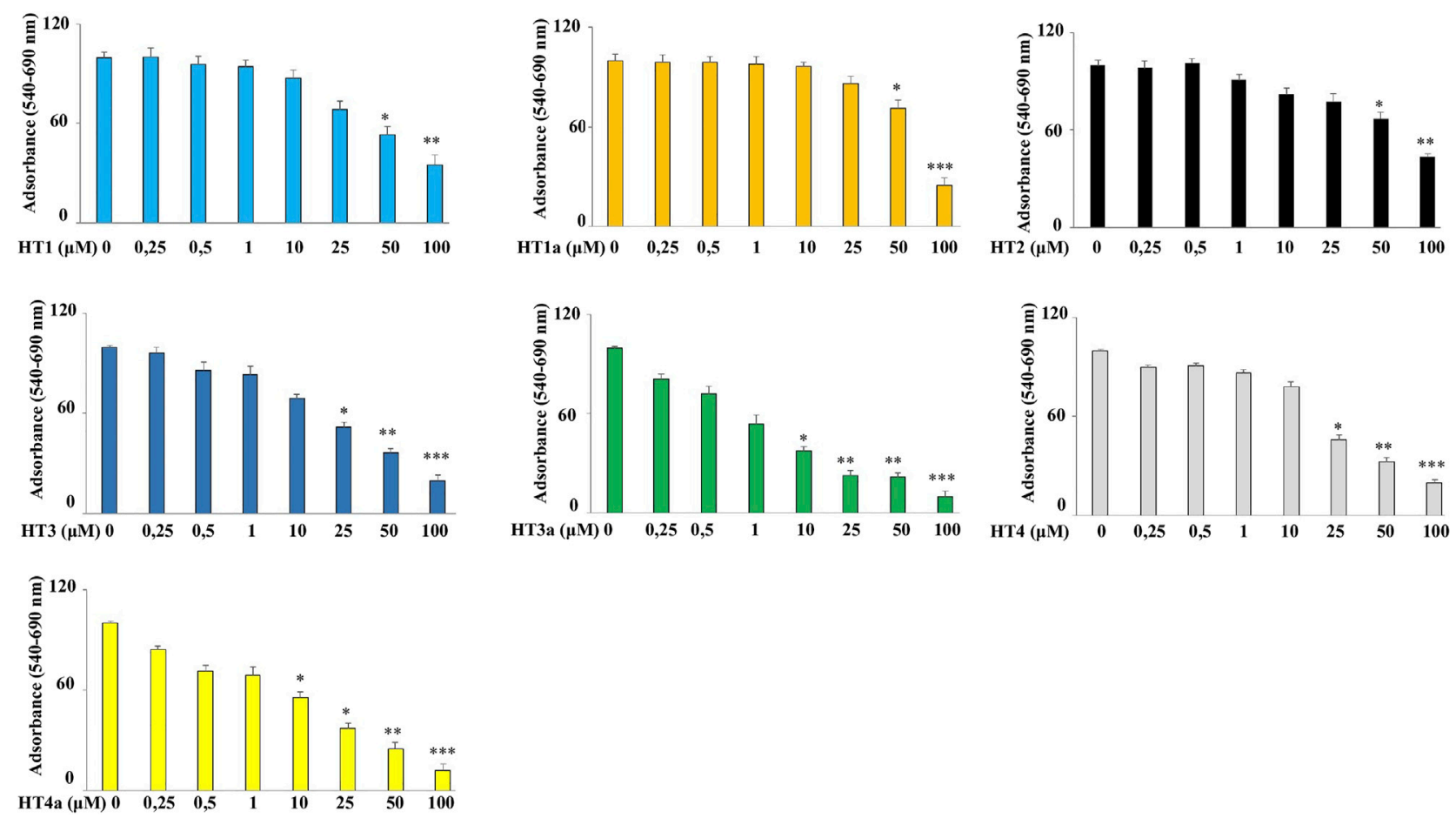

FIGURE 4 | Effects of donepezil hybrids on cell viability in human neuroblastoma cells. Human neuroblastoma (SH-SY5Y) cell line was treated with donepezil hybrids for $24 \mathrm{~h}$ at the concentrations shown in the figure. The cell viability was measured through the MTT assay. The rate of viability of untreated cells was set at 100 and all other values were related to it. Three independent experiments were carried out, with values expressed as the mean \pm standard deviation. ${ }^{*} p<0.05$ vs. control; ${ }^{\star \star} p<0.01$ vs. control; ${ }^{\star \star \star} p<0.001$ vs. control. Analysis of Variance (ANOVA) was followed by a Tukey-Kramer comparison test.

higher than $10 \mu \mathrm{M}$, probably due to the higher permeability of the acetylated form.

\subsubsection{Measurement of Reactive Oxygen Species and Neuroprotection}

Preliminary experiments were carried out in order to evaluate if donepezil hybrids had pro-oxidant effects. For this reason, $\mathrm{SH}-$ SY5Y cells were treated with the indicated compounds for $24 \mathrm{~h}$ and endogenous ROS were measured. $\mathrm{H}_{2} \mathrm{O}_{2}$ was used as positive control. As can be seen in Supplementary Figure S3, no compound has resulted in an accumulation of ROS at the indicated concentrations $(0.25-100 \mu \mathrm{M})$. Subsequently, the antioxidant properties of the compounds were evaluated and conditions of oxidative stress in neuroblastoma cells were simulated by using $\mathrm{H}_{2} \mathrm{O}_{2}$ as toxic insult. The treatment time, with $\mathrm{H}_{2} \mathrm{O}_{2}$ used to produce an accumulation of ROS (30 min), did not cause reduction in cell viability. In order to obtain a significant reduction in viability we need to treat SH-SY5Y cells for 3 hours or more (see Supplementary Figure S4). Thus, exposure to $\mathrm{H}_{2} \mathrm{O}_{2}$ for $30 \mathrm{~min}$ causes only oxidative damage. In particular, Figures $\mathbf{5 A}, \mathbf{B}$ shows the protective effect against $\mathrm{H}_{2} \mathrm{O}_{2}$, and among all concentrations used, those with the most protective effects were highlighted. The ROS values corresponding to the other concentrations are summarised in Table 2. The nitro hybrid HT2 was the more effective one to reduce the ROS amount to the physiological values. Furthermore, it is noteworthy that for the compounds HT3, the higher antioxidant effect it was measured in the acetylated form (HT3a). Then, the $\mathrm{IC}_{50}$ values are reported in Table 3, together with the potential therapeutic index of these hybrids (expressed by the ratio between the concentration of the hybrid that causes a toxic effect and the concentration that causes an antioxidant effect in neuronal cells). As shown in Table 3, all hybrids possess a neurotoxic concentration higher than the concentration showing antioxidant activity. Compound HT1 showed the best therapeutic index ratio, while for compound HT3a the lower value was calculated, although it is equal to 10 . Finally, to confirm the promising results obtained with the evaluation of antioxidant activity, we investigated whether donepezil hybrids were able to reduce the proliferative damage induced by exposure to $\mathrm{H}_{2} \mathrm{O}_{2}$. As shown in Figure 5C the cotreatment with donepezil hybrids and $\mathrm{H}_{2} \mathrm{O}_{2}$ had shown a protective effect. In particular, HT2, HT3a and HT4a showed a statistically significant increase in cell viability compared to the effect caused by treatment with hydrogen peroxide alone.

\subsection{Prediction of Pharmacokinetic Properties}

A preliminary assessment of the drug-likeness of the new hybrids was performed by using two different softwares: ADMETlab 2.0 developed by Xiong et al. (2021), and admetSAR 2.0 developed by Yang et al. (2018). The octanol/water partition coefficient (logP or AlogP, respectively) was calculated as an essential parameter for 
A
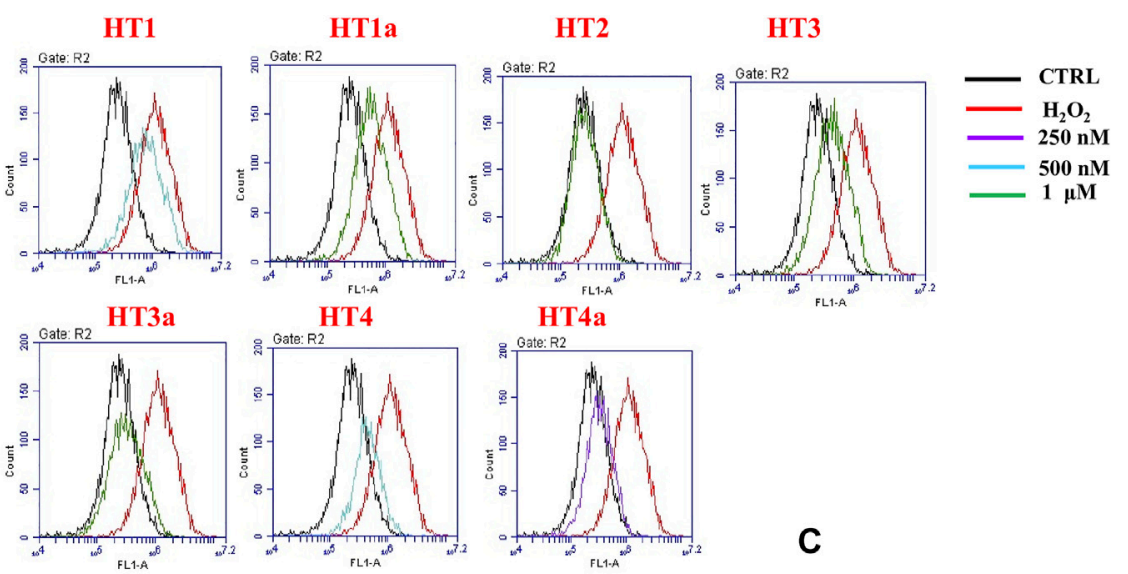

HT4

HT4a

B

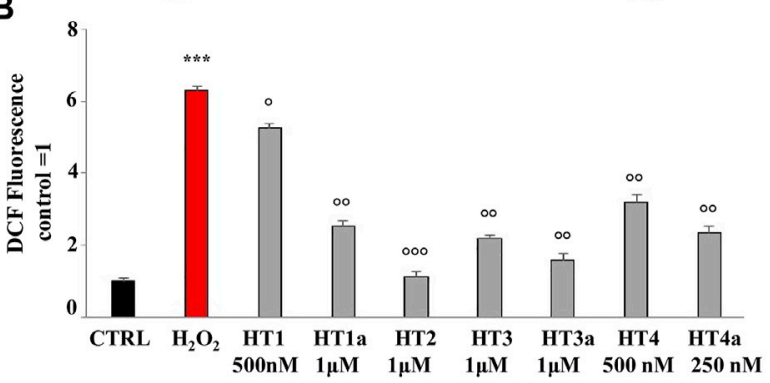

C

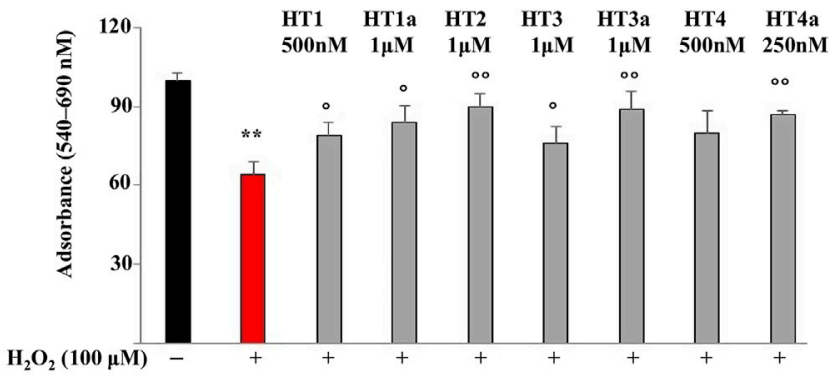

FIGURE 5 | Evaluation of ROS accumulation. (A) Protective effects of target compounds concentration against $\mathrm{H}_{2} \mathrm{O}_{2}$-induced injury in SH-SY5Y cells. The most effective concentrations were chosen. The results obtained from the cytometric analysis were displayed as overlays of the individual plots. (B) Relative quantification of ROS accumulation. The control value was arbitrarily set to 1 and all other values were related to it. A representative result of three independent experiments (which reported the same results) is shown. Values are expressed as the mean \pm standard deviation. ${ }^{* \star} p<0.001$ vs. the control. ${ }^{\circ} p<0.05$ vs. hydrogen peroxide; ${ }^{\circ} p<0.01$ vs. hydrogen peroxide; ${ }^{\circ 0} p<0.001$ vs hydrogen peroxide. Analysis of Variance (ANOVA) was followed by a Tukey-Kramer comparison test. (C) Effects of donepezil hybrids on damage induced by treatment with $\mathrm{H}_{2} \mathrm{O}_{2}$. Each value is the mean \pm standard deviation of eight wells per experimental group. Results were confirmed by three independent experiments. ${ }^{* *} p<0.01$ vs. control; ${ }^{\circ} p<0.05$ vs. hydrogen peroxide; ${ }^{\circ 0} p<0.01$ vs hydrogen peroxide. Analysis of Variance (ANOVA) was followed by a Tukey-Kramer comparison test.

TABLE 3 | IC $\mathrm{I}_{50}$ values and therapeutic index of new donepezil hybrids.

\begin{tabular}{lcc} 
Compounds & $\mathbf{I C}_{\mathbf{5 0}}(\boldsymbol{\mu} \mathbf{M})$ & Therapeutic index \\
\hline HT1 & 50 & 100 \\
HT1a & $>50$ & 50 \\
HT2 & $>50$ & 50 \\
HT3 & $>25$ & 25 \\
HT3a & $>10$ & 10 \\
HT4 & $>25$ & 50 \\
HT4a & $>10$ & 40
\end{tabular}

${ }^{a}$ Expressed as a ratio between the $I C_{50}$ value and the concentration with more antioxidant activity.

Lipinski's rule of five. In all cases, the calculated $\log \mathrm{P}$ was lower than 5, and all hybrids respect Lipinski's rule of five (Table 4). The expected permeability of these new compounds for the Caco-2 cell line, as a model for the absorption prediction after oral administration, and the BBB were also evaluated. On these two parameters, some discordant results were registered by the two prediction models. For the ADMETlab software, the predicted Caco-2 permeability (given as the $\log \mathrm{cm} / \mathrm{s}$ ) is considered excellent if it has a predicted value higher than
$-5.15 \log \mathrm{cm} / \mathrm{s}$. Among the new hybrids, only compound HT1 was found to have a predicted value lower than -5.15 , while according to the admetSAR software, compounds HT1, HT1a, and HT2 showed a certain probability of not being permeable. Otherwise, the prediction on the BBB penetration was calculated as highly favorable for all new hybrids, except for compounds HT4 and HT4a, by the admetSAR software, while the ADMETlab prediction model has considered excellent values for HT1, HT3, HT4 (range 0.7-1.0), and medium values for the others (range 0.3-0.7). All hybrids were also compared with HT alone and donepezil. It is worth noting that, while for compound HT2 the Caco-2 permeability seems to be unfavorable, for one of the ADME prediction softwares (admetSAR 2.0), the same software considers it as the only one (except Donepezil) to have a potential human oral bioavailability (data not shown).

\section{DISCUSSION}

The importance of the redox state of the cells is crucial not only for the physiological metabolism of an organism but also in the development of several age-related, cardiovascular and 
TABLE 4 | Pharmacokinetic properties as predicted in silico by software ADMETlab 2.0 and admetSAR 2.0

\begin{tabular}{|c|c|c|c|c|c|c|c|c|}
\hline \multirow[t]{2}{*}{ Compound } & \multirow[t]{2}{*}{ MW } & \multicolumn{3}{|c|}{ ADMETlab } & \multicolumn{3}{|c|}{ admetSAR } & \multirow{2}{*}{$\begin{array}{l}\text { Violation of } \\
\text { Lipinskys'rule }\end{array}$} \\
\hline & & $\log P^{a}$ & BBB penetration ${ }^{\mathbf{b}}$ & Caco-2 permeabilityc & $A \log P^{a}$ & BBB penetration ${ }^{d}$ & Caco-2 permeability & \\
\hline HT1 & 355.434 & 3.147 & 0.893 & -5.214 & 3.10 & (+) 0.9128 & (-) 0.5362 & 0 \\
\hline HT1a & 439.508 & 3.128 & 0.361 & -4.397 & 3.54 & (+) 0.9509 & (-) 0.5712 & 0 \\
\hline HT2 & 400.431 & 3.121 & 0.463 & -5.103 & 3.0 & (+) 0.9693 & (-) 0.7994 & 0 \\
\hline HT3 & 369.461 & 3.415 & 0.984 & -4.911 & 3.40 & (+) 0.9366 & (+) 0.6406 & 0 \\
\hline НТЗа & 411.498 & 3.347 & 0.667 & -4.873 & 3.62 & (+) 0.9768 & (+) 0.6086 & 0 \\
\hline HT4 & 339.435 & 3.533 & 0.947 & -4.94 & 3.39 & (-) 0.2371 & (+) 0.6969 & 0 \\
\hline HT4a & 381.472 & 3.545 & 0.401 & -4.872 & 3.61 & (-) 0.3715 & (+) 0.6051 & 0 \\
\hline $\mathrm{HT}$ & 154.165 & 0.174 & 0.037 & -4.433 & 0.63 & (-) 0.5648 & (+) 0.6302 & 0 \\
\hline Donepezil & 379.5 & 4.191 & 0.975 & $-4,793$ & 4.36 & (+) 1.0000 & (+) 0.6843 & 0 \\
\hline
\end{tabular}

${ }^{a}$ Log of the octanol/water partition coefficient.

${ }^{b}$ The output value is the probability of being $B B B+$.

${ }^{\circ}$ Optimal: higher than -5.15 Log unit.

${ }^{d}$ Value (+) or (-) indicating the probability of being $B B B(+)$ or $B B B(-)$, and the permeability or not towards Caco-2 cell line, respectively.

neoplastic diseases (Liguori et al., 2018). Diverse authors demonstrated the neuroprotective effects of the HT derivatives against not only AD (Klimova et al., 2019) but also against PD (Palazzi et al., 2018). In light of these pieces of evidence, we tried to insert the HT into the donepezil structure to exploit its neuroprotection effect. Then, we planned to also synthesize tyrosol and homovanillyl alcohol hybrids to evaluate the influence of the orthodiphenolic moiety in the tested biological activities. Noteworthy is the presence of a nitrocatechol moiety in two catechol $O$-methyltransferase (COMT) inhibitors such as tolcapone and entacapone, included in the clinical treatment of PD (Li et al., 2017; Artusi et al., 2021). Furthermore, several studies demonstrated a remarkable activity of nitro-HT derivatives in the dopamine metabolism, suggesting a putative effect against $\mathrm{PD}$ as novel and lipophilic COMT inhibitors (Gallardo et al., 2014; Trujillo et al., 2014). First, we tested the chelating ability of all these hybrids in their unprotected form, since the primary role of the acetyl groups is that of enhancing the analogues bioavailability. Only HT1 and HT2 showed metal chelating properties, highlighting the importance of the catechol moiety in the metal coordination. In particular the presence of a nitro-group allowed to chelate not only $\mathrm{Cu}(\mathrm{II})$, but also the other redox-active metal ions $\mathrm{Fe}(\mathrm{II})$, $\mathrm{Fe}(\mathrm{III})$, and $\mathrm{Zn}$ (II). The cell viability of these hybrids was evaluated to exclude a potential cytotoxic effect. Encouraging results were obtained for all of the hybrids, which did not show substantial cell death until $1 \mu \mathrm{M}$ concentration. Another crucial issue, related to the employment of natural polyphenol compounds is that, in some cases, they could act as prooxidants causing DNA damage and mutagenesis, depending on the concentration or the cellular environment (LeónGonzález et al., 2015; Eghbaliferiz and Iranshahi, 2016). To exclude a pro-oxidant effect for these new hybrids, the $\mathrm{SH}$ SY5Y neuroblastoma cell line, was treated for $24 \mathrm{~h}$ with them, using $\mathrm{H}_{2} \mathrm{O}_{2}$ as a positive control. The measurement of the endogenous ROS did not show pro-oxidant effects even at the highest concentrations for all hybrids (Supplementary Figure S3). This important result, together with the cell viability, was fundamental to assess the treatment assurance with the target compounds. Then, conditions of oxidative stress in neuroblastoma cells were simulated by using $\mathrm{H}_{2} \mathrm{O}_{2}$ as toxic insult. Some of these hybrids, HT3a and HT2, significantly showed protective effects against the damage induced by $\mathrm{H}_{2} \mathrm{O}_{2}$ at $100 \mu \mathrm{M}$. In particular, HT2 showed the highest antioxidant capacity preventing the ROS formation evoked by $\mathrm{H}_{2} \mathrm{O}_{2}$ in SH-SY5Y cells, and restoring the ROS concentration to the physiological values. In the attempt, to elucidate the mechanism of the antioxidant activity for the synthesized compounds in the unprotected form, two different and complementary chemical tests were performed. ORAC and CUPRAC tests were selected as hydrogen atom transfer (HAT)- and electron transfer (ET)based assays, respectively. The antioxidant activities of the unprotected compounds were provided in Trolox equivalent and comparatively studied against results obtained free HT. Surprisingly, discordant results were obtained for the two tests, in particular for the nitro-hybrids HT2, which seemed to be the less active in the ORAC test, although maintaining high antioxidant capacity in the CUPRAC test. On the contrary, the HT3 was the more active in the HAT-based ORAC assay, while showing a not excellent antioxidant capacity in the electron transfer (ET)-based CUPRAC assay. Although these chemical tests only possess a predictive valence, these results suggest that both the direct scavenging capability of the homovanillyl hybrid HT3 and the reducing capacity of the nitro hybrid HT2 are very important for the resulting antioxidant activity. It is worth noting that for the homovanillyl hybrid the best result on the ROS reduction was obtained by the acetylated compound HT3a, showing the importance of cell permeability in the expression of the biological activity. Moreover, these preliminary results meet the margin of safety measured for the two hybrids through the therapeutic index, (higher for compound HT2 than HT3a), allowing further investigation of these promising compounds. Neuroprotection activity against the cytotoxicity elicited by $\mathrm{H}_{2} \mathrm{O}_{2}$ was also assessed by measuring the cell viability using MTT assay. As already reported about the ROS reduction, hybrids HT2 and HT3a were able to attenuate 
cell injury against oxidative stress. Finally, to assess the potential of these compounds as drugs, some pharmacokinetics properties were calculated in silico. Two different prediction models were employed to evaluate the agreement with Lipinski's rule of five, the Caco-2 cell line permeability and the BBB penetration. For compound HT3a, the two different softwares predicted almost good results for all of the parameters, while discordant results were registered by the two prediction models for compound HT2. On one hand, the ADMETlab 2.0 software predicted medium BBB penetration and good Caco- 2 cell permeability. On the other hand, the admetSAR 2.0 software considered not excellent permeation properties together with very good value for the $\mathrm{BBB}$ penetration. Although the pharmacokinetic properties of all the hybrids are less favorable in terms of Caco-2 permeability or $\mathrm{BBB}$ penetration than those of donepezil, we obtained better results with HT2 and HT3a, if compared to just HT. Thus confirming the goal to enhance the HT activity towards the Central Nervous System, these encouraging results could suggest that these two hybrids could be eligible as drug candidates.

In conclusion, we report the synthesis of new biophenoldonepezil hybrids for the potential treatment of neurodegenerative diseases. These new synthetic hybrids were obtained in good yields. Chemical and biological assays were performed in order to evaluate their multi target directed ligand effects. These preliminary results on the antioxidant activity highlighted the efficacy of compounds HT2 and HT3a. In particular, the homovanillyl hybrid HT3a possesses a good antioxidant capacity, probably through a hydrogen transfer mechanism. The higher activity measured in the cell culture for the acetylated compound confirmed the importance of the cell membrane permeation to carry out the biological activity. As for the HT2 hybrid, bringing a nitro group onto the HT moiety, it showed interesting metal chelating properties associated with negligible cellular toxicity, as well as an electron-transfer

\section{REFERENCES}

Artusi, C. A., Sarro, L., Imbalzano, G., Fabbri, M., and Lopiano, L. (2021). Safety and Efficacy of Tolcapone in Parkinson's Disease: Systematic Review. Eur. J. Clin. Pharmacol. 77 (6), 817-829. doi:10.1007/s00228-020-03081-x

Ashraf, A., Clark, M., and So, P.-W. (2018). The Aging of Iron Man. Front. Aging Neurosci. 10, 65. doi:10.3389/fnagi.2018.00065

Balakrishnan, R., Azam, S., Cho, D.-Y., Su-Kim, I., and Choi, D.-K. (2021). Natural Phytochemicals as Novel Therapeutic Strategies to Prevent and Treat Parkinson's Disease: Current Knowledge and Future Perspectives. Oxidative Med. Cell Longevity 2021, 1-32. doi:10.1155/2021/6680935

Barnham, K. J., and Bush, A. I. (2008). Metals in Alzheimer's and Parkinson's Diseases. Curr. Opin. Chem. Biol. 12 (2), 222-228. doi:10.1016/j.cbpa.2008.02.019

Batarseh, Y. S., and Kaddoumi, A. (2018). Oleocanthal-rich Extra-virgin Olive Oil Enhances Donepezil Effect by Reducing Amyloid- $\beta$ Load and Related Toxicity in a Mouse Model of Alzheimer's Disease. J. Nutr. Biochem. 55, 113-123. doi:10.1016/j.jnutbio.2017.12.006

Blesa, J., Trigo-Damas, I., Quiroga-Varela, A., and Jackson-Lewis, V. R. (2015). Oxidative Stress and Parkinson's Disease. Front. Neuroanat. 9, 91. doi:10.3389/fnana.2015.00091

Brook, M. A., and Chan, T. H. (1983). A Simple Procedure for the Esterification of Carboxylic Acids. Synthesis 1983, 201-203. doi:10.1055/s-1983-302791983 antioxidant power. Such differentiated mechanisms of action enhance the possible biological applications of these polyphenols-donepezil hybrids, paving the way to other different targets in the neurodegenerative disorders.

\section{DATA AVAILABILITY STATEMENT}

The original contributions presented in the study are included in the article/Supplementary Material, further inquiries can be directed to the corresponding authors.

\section{AUTHOR CONTRIBUTIONS}

PC: Synthesis, CUPRAC test, Data Curation, Writing-Original paper. MO: Conceptualization, Methodology-chemistry, Supervision. Data curation, Writing - review and editing, JM: ROS measurements, Data curation, Writing - original paper. SB: ORAC test, HRMS Analysis, Data curation. GL: NMR analysis, Data curation. MM: Cell viability tests, Data curation. RA: Methodology-Biological tests, Data curation. AP: Resources, Funding acquisition, Writing-review and editing.

\section{FUNDING AND ACKNOWLEDGEMENTS}

This research has received funding from Dipartimento di Scienze della Salute, Università Magna Græcia di Catanzaro, Italy.

\section{SUPPLEMENTARY MATERIAL}

The Supplementary Material for this article can be found online at: https://www.frontiersin.org/articles/10.3389/fchem.2021.741444/ full\#supplementary-material

Bulotta, S., Oliverio, M., Russo, D., and Procopio, A. (2013). "Biological Activity of Oleuropein and its Derivatives," in Chapter 119: Biological Activity of Oleuropein and its Derivatives. Natural Products. Editors K. G. Ramawat and J. M. Merillon (Berlin: Springer-Verlag Berlin Heidelberg), 3605-3638. doi:10.1007/978-3-642-22144-6-015610.1007/ 978-3-642-22144-6_156

Caliandro, R., Pesaresi, A., Cariati, L., Procopio, A., Oliverio, M., and Lamba, D. (2018). Kinetic and Structural Studies on the Interactions of Torpedo californica Acetylcholinesterase with Two Donepezil-like Rigid Analogues. J. Enzyme Inhib. Med. Chem. 33, 794-803. doi:10.1080/ 14756366.2018.1458030

Cariati, L., Oliverio, M., Mutti, F. G., Bonacci, S., Knaus, T., Costanzo, P., et al. (2019). Hydrolases-mediated Transformation of Oleuropein into Demethyloleuropein. Bioorg. Chem. 84, 384-388. doi:10.1016/ j.bioorg.2018.12.005

Climent, M. J., Corma, A., De Frutos, P., Iborra, S., NoyVelty, M. A., Velty, A., et al. (2010). Chemicals from Biomass: Synthesis of Glycerol Carbonate by Transesterification and Carbonylation with Urea with Hydrotalcite Catalysts. The Role of Acid-Base Pairs. J. Catal. 269, 140-149. doi:10.1016/ j.jcat.2009.11.001

Corasaniti, M. T., Maiuolo, J., Maida, S., Fratto, V., Navarra, M., Russo, R., et al. (2007). Cell Signaling Pathways in the Mechanisms of Neuroprotection Afforded by Bergamot Essential Oil against NMDA- 
Induced Cell Deathin Vitro. Br. J. Pharmacol. 151 (4), 518-529. doi:10.1038/sj.bjp.0707237

Costa, M., Josselin, R., Silva, D. F., Cardoso, S. M., May, N. V., Chaves, S., et al. (2020). Donepezil-based Hybrids as Multifunctional Anti-alzheimer's Disease Chelating Agents: Effect of Positional Isomerization. J. Inorg. Biochem. 206, 111039. doi:10.1016/j.jinorgbio.2020.111039

Costanzo, P., Bonacci, S., Cariati, L., Nardi, M., Oliverio, M., and Procopio, A. (2018). Simple and Efficient Sustainable Semi-synthesis of Oleacein [2-(3,4hydroxyphenyl) Ethyl (3S,4E)-4-Formyl-3-(2-Oxoethyl)hex-4-Enoate] as Potential Additive for Edible Oils. Food Chem. 245, 410-414. doi:10.1016/ j.foodchem.2017.10.097

Costanzo, P., Cariati, L., Desiderio, D., Sgammato, R., Lamberti, A., Arcone, R., et al. (2016). Design, Synthesis, and Evaluation of Donepezil-like Compounds as AChE and BACE-1 Inhibitors. ACS Med. Chem. Lett. 7 (5), 470-475. doi:10.1021/acsmedchemlett.5b00483

Crespo, M. C., Tomé-Carneiro, J., Pintado, C., Dávalos, A., Visioli, F., and BurgosRamos, E. (2017). Hydroxytyrosol Restores Proper Insulin Signaling in an Astrocytic Model of Alzheimer's Disease. Biofactors 43 (4), 540-548. doi:10.1002/biof.1356

Cui, X., Lin, Q., and Liang, Y. (2020). Plant-Derived Antioxidants Protect the Nervous System from Aging by Inhibiting Oxidative Stress. Front. Aging Neurosci. 12, 209. doi:10.3389/fnagi.2020.00209

Cuyàs, E., Verdura, S., Lozano-Sánchez, J., Viciano, I., Llorach-Parés, L., NonellCanals, A., et al. (2019). The Extra virgin Olive Oil Phenolic Oleacein Is a Dual Substrate-Inhibitor of Catechol-O-Methyltransferase. Food Chem. Toxicol. 128, 35-45. doi:10.1016/j.fct.2019.03.049

Dias, K. S. T., de Paula, C. T., Dos Santos, T., Souza, I. N. O., Boni, M. S., Guimarães, M. J. R., et al. (2017). Design, Synthesis and Evaluation of Novel Feruloyl-Donepezil Hybrids as Potential Multitarget Drugs for the Treatment of Alzheimer's Disease. Eur. J. Med. Chem. 130, 440-457. doi:10.1016/ j.ejmech.2017.02.043

Dinda, B., Dinda, M., Kulsi, G., Chakraborty, A., and Dinda, S. (2019). Therapeutic Potentials of Plant Iridoids in Alzheimer's and Parkinson's Diseases: A Review. Eur. J. Med. Chem. 169, 185-199. doi:10.1016/ j.ejmech.2019.03.009

Eghbaliferiz, S., and Iranshahi, M. (2016). Prooxidant Activity of Polyphenols, Flavonoids, Anthocyanins and Carotenoids: Updated Review of Mechanisms and Catalyzing Metals. Phytother. Res. 30 (9), 1379-1391. doi:10.1002/ptr.5643

English, B. J., and Williams, R. M. (2009). Synthesis of ( \pm )-oleocanthal via a Tandem Intramolecular Michael Cyclization-HWE Olefination. Tetrahedron Lett. 50, 2713-2715. doi:10.1016/j.tetlet.2009.03.145

Gallardo, E., Madrona, A., Palma-Valdés, R., Trujillo, M., Espartero, J. L., and Santiago, M. (2014). The Effect of Hydroxytyrosol and its Nitroderivatives on Catechol-O-Methyl Transferase Activity in Rat Striatal Tissue. RSC Adv. 4, 61086-61091. doi:10.1039/C4RA09872B

Gambacorta, A., Tofani, D., Bernini, R., and Migliorini, A. (2007). High-Yielding Preparation of a Stable Precursor of Hydroxytyrosol by Total Synthesis and from the Natural Glycoside Oleuropein. J. Agric. Food Chem. 55 (9), 3386-3391. doi:10.1021/jf063353b

Ganguly, U., Kaur, U., Chakrabarti, S. S., Sharma, P., Agrawal, B. K., Saso, L., et al. (2021). Oxidative Stress, Neuroinflammation, and NADPH Oxidase: Implications in the Pathogenesis and Treatment of Alzheimer's Disease. Oxidative Med. Cell Longevity 2021, 1-19. doi:10.1155/2021/7086512

Gardener, H., and Caunca, M. R. (2018). Mediterranean Diet in Preventing Neurodegenerative Diseases. Curr. Nutr. Rep. 7 (1), 10-20. doi:10.1007/ s13668-018-0222-5

Khalatbary, A. R. (2013). Olive Oil Phenols and Neuroprotection. Nutr. Neurosci. 16 (6), 243-249. doi:10.1179/1476830513Y.0000000052

Kim, G. H., Kim, J. E., Rhie, S. J., and Yoon, S. (2015). The Role of Oxidative Stress in Neurodegenerative Diseases. Exp. Neurobiol. 24 (4), 325-340. doi:10.5607/ en.2015.24.4.325

Klimova, B., Novotný, M., Kuca, K., and Valis, M. (2019). Effect of an Extra-Virgin Olive Oil Intake on the Delay of Cognitive Decline: Role of Secoiridoid Oleuropein? Ndt Vol. 15, 3033-3040. doi:10.2147/NDT.S218238

León-González, A. J., Auger, C., and Schini-Kerth, V. B. (2015). Pro-oxidant Activity of Polyphenols and its Implication on Cancer Chemoprevention and
Chemotherapy. Biochem. Pharmacol. 98 (3), 371-380. doi:10.1016/ j.bcp.2015.07.017

Leri, M., Oropesa-Nuñez, R., Canale, C., Raimondi, S., Giorgetti, S., Bruzzone, E., et al. (2018). Oleuropein Aglycone: A Polyphenol with Different Targets against Amyloid Toxicity. Biochim. Biophys. Acta (Bba) - Gen. Subjects 1862 (6), 1432-1442. doi:10.1016/j.bbagen.2018.03.023

Li, J., Lou, Z., Liu, X., Sun, Y., and Chen, J. (2017). Efficacy and Safety of Adjuvant Treatment with Entacapone in Advanced Parkinson's Disease with Motor Fluctuation: A Systematic Meta-Analysis. Eur. Neurol. 78 (3-4), 143-153. doi:10.1159/000479555

Li, Q., He, S., Chen, Y., Feng, F., Qu, W., and Sun, H. (2018). Donepezil-based Multi-Functional Cholinesterase Inhibitors for Treatment of Alzheimer's Disease. Eur. J. Med. Chem. 158, 463-477. doi:10.1016/j.ejmech.2018.09.031

Liguori, I., Russo, G., Curcio, F., Bulli, G., Aran, L., Della-Morte, D., et al. (2018). Oxidative Stress, Aging, and Diseases. Cia Vol. 13, 757-772. doi:10.2147/CIA.S158513

Maiuolo, L., Feriotto, G., Algieri, V., Nardi, M., Russo, B., Di Gioia, M. L., et al. (2017). Antiproliferative Activity of Novel Isatinyl/indanyl Nitrones (INs) as Potential Spin Trapping Agents of Free Radical Intermediates. Med. Chem. Commun. 9 (2), 299-304. doi:10.1039/c7md00537g

Mori, N., and Togo, H. (2005). Facile Oxidative Conversion of Alcohols to Esters Using Molecular Iodine. Tetrahedron 61, 5915-5925. doi:10.1016/ j.tet.2005.03.097

Morris, D. R., and Levenson, C. W. (2017). Neurotoxicity of Zinc. Neurotoxicity of Metals. Springer, 303-312. doi:10.1007/978-3-319-60189-2_15

Nardi, M., Bonacci, S., Cariati, L., Costanzo, P., Oliverio, M., Sindona, G., et al. (2017). Synthesis and Antioxidant Evaluation of Lipophilic Oleuropein Aglycone Derivatives. Food Funct. 8 (12), 4684-4692. doi:10.1039/c7fo01105a

Neha, K., Haider, M. R., Pathak, A., and Yar, M. S. (2019). Medicinal Prospects of Antioxidants: A Review. Eur. J. Med. Chem. 178, 687-704. doi:10.1016/ j.ejmech.2019.06.010

Oliverio, M., Costanzo, P., Nardi, M., Calandruccio, C., Salerno, R., and Procopio, A. (2016). Tunable Microwave-Assisted Method for the Solvent-free and Catalyst-free Peracetylation of Natural Products. Beilstein J. Org. Chem. 12, 2222-2233. doi:10.3762/bjoc.12.214

Oliverio, M., Nardi, M., Cariati, L., Vitale, E., Bonacci, S., and Procopio, A. (2016). "On Water" MW-Assisted Synthesis of Hydroxytyrosol Fatty Esters. ACS Sust. Chem. Eng. 4, 661-665. doi:10.1021/acssuschemeng.5b01201

Oliverio, M., Nardi, M., Di Gioia, M. L., Costanzo, P., Bonacci, S., Mancuso, S., et al. (2021). Semi-synthesis as a Tool for Broadening the Health Applications of Bioactive Olive Secoiridoids: a Critical Review. Nat. Prod. Rep. 38, 444-469. doi:10.1039/D0NP00084A

Ou, B., Hampsch-Woodill, M., and Prior, R. L. (2001). Development and validation of an improved oxygen radical absorbance capacity assay using fluorescein as the fluorescent probe, J. Agric. Food Chem. 49, 4619-4626. doi:10.1021/jf010586o

Ozyürek, M., Bektaşoğlu, B., Güçlü, K., Güngör, N., and Apak, R. (2008). Simultaneous Total Antioxidant Capacity Assay of Lipophilic and Hydrophilic Antioxidants in the Same Acetone-Water Solution Containing 2\% Methyl-Beta-Cyclodextrin Using the Cupric Reducing Antioxidant Capacity (CUPRAC) Method. Anal. Chim. Acta 630 (1), 28-39. doi:10.1016/j.aca.2008.09.057

Palazzi, L., Bruzzone, E., Bisello, G., Leri, M., Stefani, M., Bucciantini, M., et al. (2018). Oleuropein Aglycone Stabilizes the Monomeric $\alpha$-synuclein and Favours the Growth of Non-toxic Aggregates. Sci. Rep. 8 (1), 8337. doi:10.1038/s41598-018-26645-5

Schneider, C., Remme, N., and Koschek, K. (2007). Scandium Triflate Catalyzed Transesterification of Carboxylic Esters. Synlett 2007, 0491-0493. doi:10.1055/ s-2007-967936

Singh, A., Kukreti, R., Saso, L., and Kukreti, S. (2019). Oxidative Stress: A Key Modulator in Neurodegenerative Diseases. Molecules 24 (8), 1583. doi:10.3390/ molecules 24081583

Spagnuolo, C., Napolitano, M., Tedesco, I., Moccia, S., Milito, A., and Luigi Russo, G. (2016). Neuroprotective Role of Natural Polyphenols. Ctmc 16 (17), 1943-1950. doi:10.2174/1568026616666160204122449

Squitti, R., Ventriglia, M., Siotto, M., and Salustri, C. (2017). Copper in Alzheimer's Disease. Biometals in Neurodegenerative Diseases. Amsterdam. Elsevier, 19-34. doi:10.1016/b978-0-12-804562-6.00002-6

St-Laurent-Thibault, C., Arseneault, M., Longpré, F., and Ramassamy, C. (2011). Tyrosol and Hydroxytyrosol Two Main Components of Olive Oil, Protect N2a 
Cells against Amyloid- $\beta$-Induced Toxicity. Involvement of the NF-Kb Signaling. Car 8 (5), 543-551. doi:10.2174/156720511796391845

Theodorou, V., Skobridis, K., Tzakos, A. G., and Ragoussis, V. (2007). A Simple Method for the Alkaline Hydrolysis of Esters. Tetrahedron Lett. 48, 8230-8233. doi:10.1016/j.tetlet.2007.09.074

Trujillo, M., Gallardo, E., Madrona, A., Bravo, L., Sarriá, B., González-Correa, J. A., et al. (2014). Synthesis and Antioxidant Activity of Nitrohydroxytyrosol and its Acyl Derivatives. J. Agric. Food Chem. 62 (42), 10297-10303. doi:10.1021/jf503543x

Unzeta, M., Esteban, G., Bolea, I., Fogel, W. A., Ramsay, R. R., Youdim, M. B. H., et al. (2016). Multi-Target Directed Donepezil-like Ligands for Alzheimer's Disease. Front. Neurosci. 10, 205. doi:10.3389/fnins.2016.00205

Xiong, G., Wu, Z., Yi, J., Fu, L., Yang, Z., Hsieh, C., et al. (2021). ADMETlab 2.0: an Integrated Online Platform for Accurate and Comprehensive Predictions of ADMET Properties. Nucleic Acids Res., 49, W5-W14. https://admetmesh.scbdd.com/.

Xu, W., Wang, X.-B., Wang, Z.-M., Wu, J.-J., Li, F., Wang, J., et al. (2016). Synthesis and Evaluation of Donepezil-Ferulic Acid Hybrids as Multi-Target-Directed Ligands against Alzheimer's Disease. Med. Chem. Commun. 7, 990-998. doi:10.1039/C6MD00053C

Yang, H., Lou, C., Sun, L., Li, J., Cai, Y., Wang, Z., et al. (2019). admetSAR 2.0: Web-Service for Prediction and Optimization of Chemical ADMET Properties. Bioinformatics. 35 (6), 1067-1069. http://lmmd.ecust.edu.cn/ admetsar2/.
Yang, H., Lou, C., Sun, L., Li, J., Cai, Y., Wang, Z., et al. (2018). admetSAR 2.0: Web-Service for Prediction and Optimization of Chemical ADMET Properties. Bioinformatics 35 (6), 1067-1069. doi:10.1093/ bioinformatics/bty707

Conflict of Interest: The authors declare that the research was conducted in the absence of any commercial or financial relationships that could be construed as a potential conflict of interest.

Publisher's Note: All claims expressed in this article are solely those of the authors and do not necessarily represent those of their affiliated organizations, or those of the publisher, the editors and the reviewers. Any product that may be evaluated in this article, or claim that may be made by its manufacturer, is not guaranteed or endorsed by the publisher.

Copyright (C) 2021 Costanzo, Oliverio, Maiuolo, Bonacci, De Luca, Masullo, Arcone and Procopio. This is an open-access article distributed under the terms of the Creative Commons Attribution License (CC BY). The use, distribution or reproduction in other forums is permitted, provided the original author(s) and the copyright owner(s) are credited and that the original publication in this journal is cited, in accordance with accepted academic practice. No use, distribution or reproduction is permitted which does not comply with these terms. 